\title{
Patterns of large-vessel lesions are associated with treatment outcomes in large-vessel giant cell arteritis
}

Takahiko Sugihara ( $\nabla$ takahiko.sugihara@marianna-u.ac.jp )

Tokyo Medical and Dental University https://orcid.org/0000-0002-7181-7494

Haruhito A Uchida

Okayama University Hospital: Okayama Daigaku Byoin

Hajime Yoshifuji

Kyoto University Graduate School of Medicine Faculty of Medicine: Kyoto Daigaku Daigakuin Igaku

Kenkyuka Igakubu

Yasuhiro Maejima

Tokyo Medical and Dental University: Tokyo Ika Shika Daigaku

\section{Taio Naniwa}

Nagoya City University Graduate School of Medical Sciences and Medical School: Nagoya Shiritsu

Daigaku Daigakuin Igaku Kenkyuka Igakubu

\section{Yasuhiro Katsumata}

Tokyo Women's Medical University School of Medicine: Tokyo Joshi Ika Daigaku Igakubu

\section{Takahiro Okazaki}

Saint Marianna University School of Medicine: Sei Marianna Ika Daigaku

Jun Ishizaki

Ehime University Graduate School of Medicine School of Medicine: Ehime Daigaku Daigakuin Igakukei Kenkyuka Igakubu

\section{Yohko Murakawa}

Shimane University Faculty of Medicine Graduate School of Medicine: Shimane Daigaku Igakubu Igakuka Daigakuin Igakukei Kenkyuka

\section{Noriyoshi Ogawa}

Hamamatsu University School of Medicine Library: Hamamatsu Ika Daigaku Fuzoku Toshokan

\section{Hiroaki Dobashi}

Kagawa University Faculty of Medicine Graduate School of Medicine: Kagawa Daigaku Igakubu Daigakuin Igakukei Kenkyuka

\section{Tetsuya Horita}

Hokkaido University Graduate School of Medicine School of Medicine: Hokkaido Daigaku Daigakuin Igaku Kenkyuin

\section{Yoshiya Tanaka}


University of Occupational and Environmental Health Graduate School of Medicine: Sangyo Ika Daigaku Igakubu Daigakuin Igaku Kenkyuka

\section{Shunsuke Furuta}

Chiba University Hospital: Chiba Daigaku Igakubu Fuzoku Byoin

\section{Tsutomu Takeuchi}

Keio University School of Medicine Graduate School of Medicine: Keio Gijuku Daigaku Igakubu Daigakuin Igaku Kenkyuka

\section{Yoshinori Komagata}

Kyorin University Faculty of Medicine Graduate School of Medicine: Kyorin Daigaku Igakubu Daigakuin Igaku Kenkyuka

\section{Yoshikazu Nakaoka}

National Cerebral and Cardiovascular Center: Kokuritsu Junkankibyo Kenkyu Center

\section{Masayoshi Harigai}

Tokyo Women's Medical University School of Medicine: Tokyo Joshi Ika Daigaku Igakubu

\section{Research article}

Keywords: large-vessel giant cell arteritis, aortic lesions, subclavian artery lesions, poor prognostic factor

Posted Date: October 26th, 2021

DOI: https://doi.org/10.21203/rs.3.rs-966652/v1

License: (c) (i) This work is licensed under a Creative Commons Attribution 4.0 International License.

Read Full License 


\section{Abstract}

Objective

To evaluate whether the distribution of large-vessel lesions (LVLs) in giant cell arteritis (GCA) is associated with poor treatment outcomes.

Methods

In a retrospective, multi-centric, nationwide registry of GCA patients treated with glucocorticoids between 2007 and 2014, 68 newly-diagnosed patients with LVLs were identified by imaging. Non-achievement of clinical remission by week 24 and/or relapse within 104 weeks were primarily evaluated. Factors influencing the poor treatment outcome were analyzed using Cox proportional hazard modeling. Cumulative rates and median time to the first event were analyzed by the Kaplan-Meier method and logrank testing.

Results

Aortic lesions were detected in $72.1 \%$ of the 68 GCA patients with LVLs (defined as group 2). Patients without aortic lesions were classified as having large-vessel GCA with subclavian lesions (group 1) or atypical large-vessel GCA without subclavian lesions (group 3). The mean age and proportions of PMR in group 3 were higher than those in the other two groups. Cranial lesions were observed in $66.7 \%, 55.1 \%$, and $80.0 \%$ of patients in groups 1, 2 and 3, respectively. In group 2,73.5\% had lesions in both the aorta and aortic branches. Group 1 had axillary lesions in $33.3 \%$, and carotid lesions in $44.4 \%$. Atypical LVLs in group 3 included pulmonary, hepatic or mesenteric lesions in addition to carotid lesions. Baseline doses of GCs were not different across the groups. Mean time to achievement of low-dose GC treatment (prednisolone $\leq 5 \mathrm{mg} /$ day) was also not significantly different between the groups. The cumulative rate of poor treatment outcome over the two years was $11.1 \%, 55.3 \%$ and $88.0 \%$ in the groups 1,2 and 3 , respectively; mean time to the events was significantly different among the groups. Multivariable analysis showed that the risk of poor treatment outcome was significantly higher in the group 3 .

Conclusions

The distribution of LVLs was associated with treatment outcomes in large-vessel GCA. In addition to subclavian arteries, lesions in aorta and aortic branches other than subclavian arteries should be evaluated by imaging for large-vessel GCA. The pattern of LVLs determined by imaging should be considered when determining treatment strategies for GCA.

\section{Background}

Giant cell arteritis (GCA) is characterized by cranial symptoms, polymyalgia rheumatica (PMR), and largevessel lesions (LVLs) in the aorta or its branches. The subclavian artery is a key location for LVLs in GCA (1). Aortic dilatation or aneurysm is also an important clinical feature of $\operatorname{GCA}(2,3)$ that is related to 
mortality $(4,5)$. Aortic dissection or rupture of aneurysm was reported in previous studies $(6-8)$, and aortic inflammation detected by imaging was associated with aortic dilatation (9). Based on previous reports on imaging of LVLs in patients with Takayasu arteritis (TAK) and GCA from the Diagnostic and Classification Criteria for Vasculitis cohort, it was shown that GCA patients were more likely to present with widespread lesions from the subclavian artery to the thoracic and abdominal aorta than TAK patients. In contrast, carotid lesions and/or lesions in renal, celiac or mesenteric arteries are infrequent in GCA patients (10).

Increasing dose of glucocorticoid (GC) for GCA led to GC-related complications $(11,12)$, which were associated with increased mortality rate of GCA (13), and risk factors for prolonged treatment course of glucocorticoids (GCs) are important in determining the indication of combination therapy of tocilizumab and GCs (14-16). We reported that clinical characteristics of Japanese patients newly diagnosed with GCA are similar to those of Western countries (17). In addition, imaging revealed that LVLs were present in approximately half of all GCA patients, and that they were significantly associated with an increased probability of poor treatment outcome (17). We collectively hypothesize that the distribution of LVLS determines the response to treatment in patients with GCA. To test this hypothesis, we investigated whether the distribution of LVLs was associated with poor treatment outcome in patients with GCA using two-year follow-up data from our multi-center retrospective cohort study.

\section{Methods}

\section{Database}

The members of the Japan Research Committee of the Ministry of Health, Labour, and Welfare for Intractable Vasculitis (JPVAS) participated in this retrospective multi-center study, which was approved by the institutional review board of Tokyo Medical and Dental University (approval number: M2000-208401). The details were described in a previous study (17). The 68 newly-diagnosed GCA patients with LVLs were diagnosed between 2007 and 2014 in each facility based on imaging of LVLs with and without temporal arterial biopsy (TAB). Data for two-year follow-up post-initiation of GC treatment were collected, using pre-defined case-report forms at 4, 8, 24, 52, 76 and 104 weeks after starting treatment.

\section{Outcomes}

The primary endpoint was an event related to a poor treatment outcome (classified as failure to achieve clinical remission by week 24 or relapse within 104 weeks). Clinical remission was defined as absence of active disease as described in a previous report (17). Active disease at baseline was defined as having clinical signs and symptoms in cranial and large-vessel areas, or suffering from PMR, and/or elevation of CRP levels. We distinguished persistent ischemic signs and symptoms (i.e., visual manifestations or claudication) from GCA damage at week 24 after starting treatment as follows: if the signs and symptoms of active disease at baseline persisted without worsening for six months or longer and the CRP level was normalized, these were considered to reflect the damage at week 24 after starting treatment. A patient was determined to have a relapse as described previously (17); if they had either one 
of the signs or symptoms newly appearing or worsening after achievement of clinical remission, or if they showed deterioration in the LVLs by imaging. Re-elevation of the CRP level above the limit of the normal range $(<0.3 \mathrm{mg} / \mathrm{dl})$ but without any clinical manifestations was considered as a relapse only if other causes of increased CRP such as infection were excluded and at that time treatment was intensified. Three investigators ( $\mathrm{HAU}, \mathrm{HY}, \mathrm{YN}$ ) independently confirmed clinical findings at a time of relapse as described in the previous study (17).

\section{Imaging of LVLs at baseline}

The site investigators reported wall thickening, stenosis, aneurysm, or dissection in anatomical sites of lesions of aortic branches and aortic lesions based on the results of at least one of the following techniques: computed tomography (CT), CT angiography (CTA), magnetic resonance imaging (MRI), or magnetic resonance angiography (MRA). Fluorodeoxyglucose (FDG) uptake in the arterial wall on positron emission tomography (PET)-CT were also reported. Based on the imaging findings, the GCA with LVLs were categorized into two phenotypes: GCA with aortic lesions (group 2) or without aortic lesions. The latter were subdivided into large-vessel GCA (LV-GCA) with subclavian lesions (group 1: LV-GCA without aortic lesions) and that with lesions of aortic branches without subclavian lesions (group 3: atypical LV-GCA without aortic lesions).

\section{Statistics}

Student's t test and the Mann-Whitney test were used to compare continuous variables depending on their distribution, and the chi-squared test and Fisher's exact test were used for categorical variables. One-way analysis of variance was used to compare three groups. Cumulative rates and median time to the first event of the poor treatment outcome or the achievement of low-dose GC (prednisolone $\leq 5$ $\mathrm{mg} /$ day) treatment within 104 weeks were analyzed using the Kaplan-Meier method and the log-rank testing. Patients who did not achieve clinical remission by week 24 were deemed to have had an event of the poor treatment outcome at week 0 as described in the previous study $(17,18)$. Univariable and multivariable analysis for associated factors with the event of poor treatment outcomes during 104 weeks were conducted by using the Cox proportional hazard modeling. All analyses were performed using SPSS version 26 (IBM, Armonk, NY, USA). All reported $p$-values are two-tailed and the level of significance is $p<0.05$.

\section{Results}

\section{Patients' characteristics}

Case report forms of 68 newly-diagnosed GCA patients with LVLs were assessed. All patients were of Asian ethnicity. The mean (standard deviation [S.D.]) age was 70.5 (7.0) years, and $70.6 \%$ were women. Twenty-seven (39.7\%) of the 68 patients were diagnosed by both positive TAB and positive imaging of LVLs, and $41(60.3 \%)$ by positive imaging of LVLs only. Twenty-nine (42.6\%) did not meet the ACR GCA classification criteria. Cranial lesions and PMR were observed in $41(60.3 \%)$ and $23(33.8 \%)$ of the 68 
patients with LVLs, respectively. Wall thickening or FDG uptake in the arterial wall were common (70.6\%), but the proportion of aortic aneurysms was low (8.8\%) at baseline. Subclavian lesions were also frequently observed (57.4\%), and $25 \%$ had stenosis of the aortic branches (Table 1 ). The initial mean dose (S.D.) of prednisolone was $0.74(0.26) \mathrm{mg} / \mathrm{kg} / \mathrm{day}$, and $20.6 \%$ received MTX for remission induction therapy, $4.4 \%$ cyclophosphamide, and $13.2 \%$ azathioprine. 
Table 1

Clinical characteristics and imaging findings of three groups of LV-GCA phenotype.

\begin{tabular}{|c|c|c|c|c|c|}
\hline & $\begin{array}{l}\text { Enrolled } \\
\text { patients } \\
(n=68)\end{array}$ & $\begin{array}{l}\text { Group } \\
1 \\
(n=9)\end{array}$ & $\begin{array}{l}\text { Group } 2 \\
(n=49)\end{array}$ & $\begin{array}{l}\text { Group } 3 \\
(n=10)\end{array}$ & $\begin{array}{l}P \\
- \\
\text { value }\end{array}$ \\
\hline Age, years, mean (S.D.) & $70.5(7.0)$ & $\begin{array}{l}70.6 \\
(7.3)\end{array}$ & $69.9(6.7)$ & $\begin{array}{l}73.6 \\
(8.0)\end{array}$ & 0.842 \\
\hline Female patients, $\%$ & 70.6 & 77.8 & 69.4 & 70.0 & 0.878 \\
\hline Cranial lesions at baseline, $\%$ & 60.3 & 66.7 & 55.1 & 80.0 & 0.312 \\
\hline PMR, \% & 33.8 & 33.3 & 30.6 & 50.0 & 0.498 \\
\hline CRP at baseline, $\mathrm{mg} / \mathrm{dl}$, mean (S.D.) & $\begin{array}{l}7.3 \\
(5.1)\end{array}$ & $\begin{array}{l}3.5 \\
(3.5)\end{array}$ & $8.0(5.3)$ & $7.6(4.1)$ & 0.248 \\
\hline Left carotid, \% & 39.7 & 44.4 & 38.8 & 40.0 & 0.950 \\
\hline Right carotid, \% & 32.4 & 33.3 & 36.7 & 10.0 & 0.257 \\
\hline Vertebral, \% & 7.4 & 22.2 & 4.1 & 10.0 & 0.150 \\
\hline Brachiocephalic, \% & 30.9 & 33.3 & 36.7 & 0 & - \\
\hline Any subclavian lesions, \% & 57.4 & 100 & 61.2 & 0 & - \\
\hline Left subclavian, \% & 52.9 & 88.9 & 57.1 & 0 & - \\
\hline Right subclavian, \% & 44.1 & 55.6 & 51.0 & 0 & - \\
\hline Left axillary, \% & 20.6 & 33.3 & 20.4 & 10.0 & 0.454 \\
\hline Right axillary, \% & 16.2 & 33.3 & 16.3 & 0 & 0.143 \\
\hline Pulmonary, \% & 1.5 & 0 & 0 & 10.0 & - \\
\hline Ascending aorta, \% & 30.9 & 0 & 42.9 & 0 & - \\
\hline Aortic arch, \% & 50.0 & 0 & 69.4 & 0 & - \\
\hline Descending thoracic aorta, \% & 50.0 & 0 & 69.4 & 0 & - \\
\hline Abdominal aorta, \% & 54.4 & 0 & 73.5 & 0 & - \\
\hline
\end{tabular}

One-way analysis of variance was used to compare three groups.

Group 1: subclavian artery lesions without aortic lesions (typical LV-GCA without aortic lesions); Group 2: aortic lesions with or without subclavian artery lesions; Group 3: Lesions of aortic branches without aortic lesions and subclavian artery lesions (atypical LV-GCA without aortic lesions)

AZA: azathioprine; CRP: C-reactive protein; CY: cyclophosphamide; LV: large-vessel; LVLs: large-vessel lesions; PMR: polymyalgia rheumatica; S.D.: standard deviation. 


\begin{tabular}{|c|c|c|c|c|c|}
\hline & $\begin{array}{l}\text { Enrolled } \\
\text { patients } \\
(n=68)\end{array}$ & $\begin{array}{l}\text { Group } \\
1 \\
(n=9)\end{array}$ & $\begin{array}{l}\text { Group } 2 \\
(n=49)\end{array}$ & $\begin{array}{l}\text { Group } 3 \\
(n=10)\end{array}$ & $\begin{array}{l}P \\
- \\
\text { value }\end{array}$ \\
\hline Renal, \% & 5.9 & 11.1 & 6.1 & 0 & 0.584 \\
\hline Hepatic, \% & 1.5 & 0 & 0 & 10.0 & - \\
\hline Mesenteric, \% & 1.5 & 0 & 0 & 10.0 & - \\
\hline Iliac or femoral artery, \% & 11.8 & 22.2 & 10.2 & 10.0 & 0.579 \\
\hline Stenosis of aortic branches, \% & 25.0 & 55.6 & 18.4 & 30.0 & 0.056 \\
\hline Aneurysm of aorta, $\%$ & 8.8 & 0 & 12.2 & 0 & - \\
\hline $\begin{array}{l}\text { Initial dose of prednisolone, } \\
\mathrm{mg} / \mathrm{kg} / \text { day, mean (S.D.) }\end{array}$ & $0.74(0.26)$ & $\begin{array}{l}0.59 \\
(0.23)\end{array}$ & $0.77(0.24)$ & $\begin{array}{l}0.75 \\
(0.31)\end{array}$ & 0.743 \\
\hline MTX for induction therapy, (\%) & 20.6 & 0 & 24.5 & 20.0 & 0.248 \\
\hline MTX for relapse, $\%$ & 19.1 & 0 & 24.5 & 10.0 & 0.167 \\
\hline CY for induction therapy, \% & 4.4 & 11.1 & 2.0 & 10.0 & 0.309 \\
\hline CY for relapse, $\%$ & 2.9 & 0.0 & 2.0 & 0.0 & 0.821 \\
\hline AZA for induction therapy, \% & 13.2 & 11.1 & 16.3 & 0.0 & 0.374 \\
\hline AZA for relapse, \% & 5.7 & 0.0 & 4.1 & 0.0 & 0.671 \\
\hline \multicolumn{6}{|c|}{ One-way analysis of variance was used to compare three groups. } \\
\hline \multicolumn{6}{|c|}{$\begin{array}{l}\text { Group 1: subclavian artery lesions without aortic lesions (typical LV-GCA without aortic lesions); } \\
\text { Group 2: aortic lesions with or without subclavian artery lesions; Group 3: Lesions of aortic branches } \\
\text { without aortic lesions and subclavian artery lesions (atypical LV-GCA without aortic lesions) }\end{array}$} \\
\hline
\end{tabular}

Clinical characteristics and imaging findings of patients stratified by the three groups of LVLs.

Based on the imaging findings, patients with LVLs were stratified into three groups as described in the Methods. Group 1 (LV-GCA without aortic lesions) consisted of 9 patients (13.2\%), group 2 (GCA with aortic lesions) of 49 (72.1\%), and group 3 (atypical LV-GCA without aortic lesions) of 10 (14.7\%). The mean age and proportion of PMR in group 3 was higher than in the other two groups (Table 1). Cranial lesions were observed in $66.7 \%, 55.1 \%$, and $80.0 \%$ of patients in groups 1,2 and 3 , respectively. In group 2,36 of the 49 patients had lesions in both the aorta and aortic branches, with left subclavian lesions reported in 28 (57.1\%), and right subclavian lesions in $25(51.0 \%)$. Thirteen (26.5\%) of the 49 had isolated aortic lesions. There were axillary lesions in $33.3 \%$ of group 1 , and carotid lesions in $44.4 \%$. Stenosis of aortic branches was more frequently observed in group 1 (55.6 \%), compared to group 2 (18.4\%) and 
group 3 (30.0\%). Atypical large-vessel lesions in group 3 included pulmonary, hepatic or mesenteric lesions in addition to carotid or vertebral lesions. Baseline doses of GCs were not different across the groups. Mean time to achievement of low-dose GC treatment (prednisolone $\leq 5 \mathrm{mg} /$ day) was also not significantly different between the groups as follows: group 1: 459 days (95\% confidence interval [CI] 314604); group 2: 531 days (95\% Cl 471-591); and group 3: 497 days (95\% Cl 361-634) (Figure 1A). Methotrexate (MTX) was administered for initial treatment in $0 \%$ in group $1,24.5 \%$ in group $2,20 \%$ in group 3 , and for relapse in $0 \%$ in group $1,24.5 \%$ in group 2 , and $10.0 \%$ in group 3 (Table 1 ). No patients received biologic agents.

\section{Treatment Outcomes Of Gca With Lvls}

Overall, 35 (51.5\%) of the 68 GCA patients with LVLs had an event of the poor treatment outcome. Eleven patients failed to achieve clinical remission by week 24 . Relapse after achieving clinical remission was reported in 24 patients, 9 between week 0 and 24, 12 between week 24 and 52, and 3 between week 52 and 104 (Figure 2). Imaging progression of LVLs were reported in 9 of the 49 in the group 2 and in 2 of the 10 in the group 3. Progression of thoracic aortic lesions, abdominal aortic lesions, and subclavian lesions were reported in 3, 3, 3 of the group 2 and 1, 0, 0 of the group 3, respectively, at the time of event of poor treatment response. One of the group 2 had cranial signs and symptoms, and one of the group 2 and one of the group 3 had PMR at the event. The elevation of CRP without clinical signs and symptoms was most frequently reported as clinical signs and symptoms at the time of event of poor treatment response (Table 2).

Table 2 Clinical signs and symptoms of patients at the time of event of poor treatment outcome 


\begin{tabular}{|c|c|c|c|}
\hline & Group 1 n=1 & $\begin{array}{l}\text { Group } 2 \\
n=26\end{array}$ & $\begin{array}{l}\text { Group } 3 \\
\mathrm{n}=8\end{array}$ \\
\hline $\begin{array}{l}\text { Thoracic } \\
\text { aortic } \\
\text { lesions }\end{array}$ & None & $\begin{array}{l}\text { - Rupture of ascending aorta }(n=1) \\
\text { - Progression of stenosis of left } \\
\text { subclavian and ascending aorta } \\
\left(n=1^{*}\right) \\
\text { - Newly detected wall thickening of } \\
\text { ascending aorta }(n=1)\end{array}$ & $\begin{array}{l}\text { - Dissection of } \\
\text { descending thoracic } \\
\text { aorta }(n=1)\end{array}$ \\
\hline $\begin{array}{l}\text { Abdominal } \\
\text { aortic } \\
\text { lesions }\end{array}$ & None & $\begin{array}{l}\text { - Progression of abdominal } \\
\text { aneurysm }(n=1) \\
\text { - Expansion of abdominal aorta } \\
(n=1) \\
\text { - Newly detected wall thickening of } \\
\text { abdominal aorta }(n=1)\end{array}$ & None \\
\hline $\begin{array}{l}\text { Subclavian } \\
\text { lesions }\end{array}$ & None & $\begin{array}{l}\text { - Progression of stenosis of left } \\
\text { subclavian and ascending aorta } \\
\left(n=1^{\star}\right) \\
\text { - Newly detected wall thickening of } \\
\text { subclavian artery }(n=1) \\
\text { - Expansion of right subclavian } \\
\text { artery }(n=1)\end{array}$ & None \\
\hline $\begin{array}{l}\text { Other large- } \\
\text { vessel } \\
\text { lesions }\end{array}$ & None & - Stenosis of vertebral artery $(n=1)$ & $\begin{array}{l}\text { - Stenosis of iliac } \\
\text { artery }(n=1)\end{array}$ \\
\hline $\begin{array}{l}\text { Cranial } \\
\text { signs } \\
\text { and } \\
\text { symptoms }\end{array}$ & None & - Headache $(n=1)$ & None \\
\hline Others & $\begin{array}{l}\text { Persistent CRP } \\
\text { elevation } \\
(n=1)\end{array}$ & $\begin{array}{l}\text { - PMR }(n=1) \\
\text { - Systematic symptoms }(n=1) \\
\text { - Persistent CRP elevation }(n=14)\end{array}$ & $\begin{array}{l}\text { - } \operatorname{PMR}(n=1) \\
\text { - } \text { Systematic } \\
\text { symptoms }(n=1) \\
\text { - Persistent CRP } \\
\text { elevation }(n=4)\end{array}$ \\
\hline
\end{tabular}

*clinical signs and symptoms of a same patient

CRP: C-reactive protein; PMR: polymyalgia rheumatica.

Cumulative rate of poor treatment outcomes in patients stratified by the three groups of LVLs 
The cumulative rate of events of poor treatment outcome over the two-year follow-up was $11.1 \%$ for patients in group $1,55.3 \%$ in group 2 , and $88.0 \%$ in group 3 . Mean time to an event of the poor treatment outcome was significantly different within each pair of the groups (Figure 1B). Univariable and multivariable Cox proportional hazards modeling showed that patients in group 1 were likely to have a reduced risk (hazard ratio [HR] 0.14, 95\% $\mathrm{Cl} 0.02-1.03, \mathrm{p}=0.054$ ), while group 3 patients had a significantly increased risk of poor treatment outcome (HR 2.22, 95\% Cl 1.06-4.68, $p=0.054)$ (Table 3).

Table 3

Associations of poor treatment outcome with phenotype of LVLs

\begin{tabular}{|c|c|c|c|c|}
\hline & \multicolumn{2}{|l|}{ Univariable analysis } & \multicolumn{2}{|l|}{ Multivariable analysis } \\
\hline & Hazard ratio $(95 \% \mathrm{Cl})$ & value & Hazard ratio $(95 \% \mathrm{Cl})$ & $\begin{array}{l}P \text { - } \\
\text { value }\end{array}$ \\
\hline Group 1 & $0.61(0.30-1.23)$ & 0.167 & $0.14(0.02-1.03)$ & 0.054 \\
\hline Group 2 & $0.97(0.57-1.64)$ & 0.899 & $1.03(0.60-1.77)$ & 0.923 \\
\hline Group 3 & $2.27(1.14-4.51)$ & 0.020 & $2.22(1.06-4.68)$ & 0.035 \\
\hline \multicolumn{5}{|c|}{$\begin{array}{l}\text { Univariable and multivariable analyses of factors associated with an event of poor treatment } \\
\text { outcome within } 104 \text { weeks were conducted using the Cox proportional hazard model. Age, any crania } \\
\text { symptoms, and polymyalgia rheumatica were selected as covariates of interest. }\end{array}$} \\
\hline
\end{tabular}

\section{Discussion}

In the current study, approximately $70 \%$ of GCA patients with LVLs confirmed by imaging exhibited aortic lesions. One half of these patients with aortic lesions (group 2) failed to achieve clinical remission by 24 weeks or relapsed after achieving clinical remission within the two-year follow-up. Patients with subclavian arteritis without aortic lesions (group 1) had the better treatment response than the group 2, and atypical large vessel-GCA without both aortic and subclavian artery involvement (group 3) had the worst prognostic phenotype of LV-GCA. Interestingly, the mean age of onset in the atypical LV-GCA (group 3) was older compared to the typical LV-GCA with subclavian lesions (group 1) or aortic lesions (group 2), and cranial lesions and PMR were common findings in the atypical LV-GCA (group 3).

Prolonged aortic inflammation might contribute to slowly progressive vascular damage in GCA patients who have prior $\operatorname{LVLs}(9,19,20)$, and serious complications in the aortas of patients with GCA could result in increased mortality $(4,6,7,20,21)$. LVLs were predictive factors of new cardiovascular events of GCA (22). Our JPVAS cohort showed that LVLs were associated with an increased probability of poor treatment outcome of GCA, especially when present in the aorta rather than its branches (17). Notably, the present study revealed that GCA patients with aortic lesions, mainly due to aortic wall inflammation, were more resistant to initial therapy than patients with subclavian arteritis without aortic lesions. Our results 
indicate that the aortic wall inflammation served as a factor predicting poor response to initial treatment. Subclavian / axillary artery was easier to assess by ultrasonography than aortic lesions, but the aortic wall inflammation by MRI or PET-CT should be also assessed to determine disease activity of GCA (23, 24).

Patients with subclavian artery involvement with or without aortic lesions had a higher relapse rate than in patients with cranial GCA without LVLs (25). Our JPVAS cohort found a better treatment response in cranial GCA without LVLs (17) and subclavian arteritis without aortic lesions (group1). However, arm claudication due to subclavian artery stenosis at baseline was most frequently counted as damage at week 24 in the present study (Figure 2). Recent imaging studies also showed arm claudication was associated with subclavian artery damage, but not inflammation (26). This is in line with the results of the evaluation of damage in previous prospective studies (27).

Recent meta-analysis showed the overall prevalence of GCA relapse was about $50 \%$ with a high heterogeneity, and shorter GC regimens in randomized controlled trials was associated with the higher relapse rate (28). In our observational studies, patients with aortic lesions (group 2) had similar relapse rate with the meta-analysis, and group 1 and group 3 had clearly different relapse rate, even though mean time to achievement of low-dose GC treatment was similar among 3 groups.

Previous study has shown that new lesions by imaging may appear even in the absence of typical signs and symptoms, underscoring the necessity of comprehensive vascular imaging (29). Vessel wall signals by MRI (30) or vascular inflammation by PET-CT (31) persisted even after the disappearance of clinical signs and symptoms. Our study also indicated the elevation of CRP without clinical signs and symptoms was a common finding in GCA patients with LVLs, emphasizing the importance of imaging in evaluating vascular inflammation (32-34), although CRP was not useful to evaluate cranial signs and symptoms and PMR at the time of relapse of $\operatorname{GCA}(35,36)$.

Gribbons et al. sought to identify subsets of GCA, and showed that GCA with LVLs was divisible into two groups based on the involvement of temporal artery (37). TCZ improved clinical outcomes not only in GCA patients with cranial lesions but also in patients who presented with LVLs and PMR without cranial lesions (38). The present study showed proportion of cranial lesions were similar between LV-GCA patients with and without poor treatment outcome.

Group 3 in the present study was considered atypical LV-GCA because the patients did not have both aortic and subclavian artery lesions. Interestingly, the pattern of LVLs in group 3 had imaging features similar to TAK (10), while the mean age of onset was older compared to the other two groups, and high proportions of cranial lesions and PMR were present. A recent prospective study also documented progression of arterial stenosis or dilation in the relatively infrequent vascular lesions of GCA (29). Thus, the older age of onset and higher proportion of cranial lesions in group 3 were likely to be those of cranial GCA $(1,25)$, but these had atypical LVLs. 
There are some limitations to this study associated with its retrospective design, as described in the previous report (17). First, there was no uniform treatment protocol and imaging examination for assessment of LVLs in the 3 groups. Second, there was a potential indication bias in selecting treatment because the attending physician might intensify treatment for patients with atypical lesions, such as pulmonary vasculitis. However, we did not find a significant difference among groups regarding the dose of GCs and the choice of immunosuppressive drugs. Third, although there might be some imprecision due to the relatively small sample size, significant differences among the three groups were obvious.

\section{Conclusions}

The distribution of LVLs was associated with treatment outcomes in large-vessel GCA. In addition to the conventionally screened subclavian artery, involvement of aorta and other large arteries should be evaluated in patients with GCA. The pattern of LVLs determined by imaging should be considered when determining treatment strategies for GCA.

\section{Abbreviations}

ACR

American College of Rheumatology

AEs

adverse events

AZA

azathioprine

$\mathrm{Cl}$

confidence interval

CRP

C-reactive protein

CY

cyclophosphamide

FDG

18fluorodeoxyglucose

GCA

giant cell arteritis (GCA)

GCs

Glucocorticoids

JPVAS

Japan Research Committee of the Ministry of Health

Labour

and Welfare for Intractable Vasculitis

LVLS 
Large-vessel lesions

LV

large-vessel

MTX

methotrexate

PET

positron emission tomography

PMR

polymyalgia rheumatica

PSL

prednisolone

S.D.

standard deviation

$\mathrm{TAB}$

temporal arterial biopsy.

\section{Declarations}

\section{Ethics approval and consent to participate}

This study was conducted in accordance with the Declaration of Helsinki and the Ethical Guidelines for Epidemiological Research in Japan. The institutional review board of Tokyo Medical and Dental University as main center (approval number: M2000-2084-01) and the additional institutions approved our retrospective study without personally identifiable information. Patients received posters informing the present study, or the posters were displayed in outpatient clinic of each facility.

\section{Consent for publication}

Not applicable

\section{Availability of data and materials}

All of the data supporting the conclusions of this article are included within the article.

\section{Competing interests}

TS has received research grants and/or honoraria from Abbvie Japan Co., Ltd., AsahiKASEI Co., Ltd., Astellas Pharma Inc., Ayumi Pharmaceutical, Bristol Myers Squibb K.K., Chugai Pharmaceutical Co., Ltd., Daiichi Sankyo., Eli Lilly Japan K.K., Mitsubishi-Tanabe Pharma Co., Ono Pharmaceutical, Pfizer Japan Inc., Takeda Pharmaceutical Co. Ltd., and UCB Japan Co. Ltd.. Tokyo Medical and Dental University received unrestricted research grants for Department of Lifetime Clinical Immunology from Ayumi Pharmaceutical Corporation, Chugai Pharmaceutical Co., Ltd., CSL Behring K.K., Japan Blood Products Organization, and UCB Japan Co. Ltd. HAU belongs to the Department of Chronic Kidney 
Disease and Cardiovascular Disease which is endowed by Olba Healthcare Holdings, Chugai Pharmaceutical Company, Boehringer Ingelheim and Terumo Corporation. HY has received lecture fees from Chugai Pharmaceutical Co., Ltd. and Nihon Medi-Physics Co., Ltd. YM have received honoraria from Chugai Pharmaceutical Co., Ltd. TN has received research grants and lecture fees from Chugai Pharmaceutical Co., Ltd. YK has received honoraria from Chugai Pharmaceutical Co., Ltd., GlaxoSmithkline K.K., Sanofi K.K., Pfizer Japan Inc., and Asahi Kasei Pharma Corp. YM has received honoraria from Abbvie, Astellas, Ayumi Pharmaceutical, Bristol Myers Squibb, Chugai Pharmaceutical, Eisai Pharmaceutical, Janssen Pharmaceutical, Kissei Pharmaceutical, Nippon Kayaku, Pfizer Pharmaceutical, Takeda Pharmaceutical, UCB Pharmaceutical, and has received research grant support from Asahi Kasei Pharma, Chugai Pharmaceutical, Daiichi Sankyo, Eisai Pharmaceutical, Mitsubishi Tanabe Pharma, Nippon Kayaku, AbbVie Japan, Gilead Sciences Inc, Janssen Pharmaceutical, and Teijin Pharma. HD has received honoraria from Abbvie, Astellas, Ayumi Pharmaceutical, Chugai Pharmaceutical, Eisai Pharmaceutical, UCB Pharmaceutical, and has received research grant support from Asahi Kasei Pharma, Chugai Pharmaceutical, Daiichi Sankyo, Mitsubishi Tanabe Pharma, Nippon Kayaku, AbbVie Japan and Teijin Pharma. YT has received consulting fees, speaking fees, and/or honoraria from Daiichi-Sankyo, Astellas, Pfizer, Mitsubishi-Tanabe, Bristol-Myers, Chugai, YL Biologics, Eli Lilly, Sanofi, Janssen, UCB and has received research grants from Mitsubishi-Tanabe, Takeda, Bristol-Myers, Chugai, Astellas, Abbvie, MSD, Daiichi-Sankyo, Pfizer, Kyowa- Kirin, Eisai, Ono. TT has received research grants from Astellas, Chugai, Daiichi Sankyo, Takeda, AbbVie, Asahi Kasei, Mitsubishi Tanabe, Pfizer, Eisai, AYUMI, Nippon Kayaku, and Novartis, has received consulting fees from Astra Zeneca, Eli Lilly, Novartis, Mitsubishi Tanabe, AbbVie, Nippon Kayaku, Janssen, Astellas, Taiho, Chugai, Taisho Toyama, GlaxoSmithKline, and UCB, and has served on speakers' fees for AbbVie, Bristol-Myers Squibb, Chugai, Mitsubishi Tanabe, Pfizer, Astellas, Daiichi Sankyo, Eisai, Sanofi, Teijin, Takeda, and Novartis. YK has received consulting fees from Chugai, Kyowa Hakko Kirin, Asahi Kasei, UCB and speakers' fees from Bristol-Myers Squibb, Eli Lilly, Janssen, Novartis, Daiichi Sankyo, AbbVie, Nippon Shinyaku, Towa. YN has received research grants from Bayer Yakuhin, Ltd, and has received consulting fees and/or lecture fees and/or research grants from Chugai, has received consulting fees and/or lecture fees from AbbVie, has received consulting fees and/or lecture fees from Janssen, and has received lecture fees from Astellas, Takeda, Daiichi Sankyo, Actelion, and Japan Blood Products Organization (JB). MH has received research grants and/or honoraria from Abbott Japan Co., Ltd.; Astellas Pharma Inc.; Bristol-Myers Squibb K.K.; Chugai Pharmaceutical Co., Ltd.; Eisai Co., Ltd.; Janssen Pharmaceutical K.K.; Mitsubishi Tanabe Pharma Co.; Santen Pharmaceutical Co., Ltd.; Takeda Pharmaceutical Co., Ltd.; Teijin Pharma, Ltd.; and Pfizer Japan Inc. TO, JI, NO, HD, TH and SF have nothing to declare.

\section{Funding}

This work was supported by grants from the Ministry of Health, Labour and Welfare, Japan (H29nanchitou (nan)-ippan-018) and the Japan Agency for Medical Research and Development (AMED) (JP17ek0109121).

\section{Authors' contributions}


T sugihara, Y Nakaoka and M Harigai were responsible for conception and design, data collection and analysis, critical revision, and manuscript writing. HAU, HY, and $Y N$ were responsible for conception and design, data collection and analysis, and critical revision. TN, YK, TO, JI, YM, NO, HD, TH, YT, SF, TT, and YK were responsible for data collection and analysis, and critical revision. All authors read and approved the final manuscript.

\section{Acknowledgments}

The authors would like to acknowledge all investigators in Japan Research Committee of the Ministry of Health, Labour, and Welfare for Intractable Vasculitis (JPVAS). In addition to the authors, the following investigators and institutions participated in this study: Department of Hematology, Clinical Immunology and Infectious Diseases, Ehime University Graduate School of Medicine (Hitoshi Hasegawa), Department of Internal Medicine, Juntendo University Koshigaya Hospital (Shigeto Kobayashi); Niigata Rheumatic Center (Satoshi Ito); Niigata Prefectural Shibata Hospital (Noriyuki Homma).

\section{References}

1. Brack A, Martinez-Taboada V, Stanson A, Goronzy JJ, Weyand CM. Disease pattern in cranial and large-vessel giant cell arteritis. Arthritis Rheum. 1999;42(2):311-7.

2. Garcia-Martinez A, Arguis P, Prieto-Gonzalez S, Espigol-Frigole G, Alba MA, Butjosa M, et al. Prospective long term follow-up of a cohort of patients with giant cell arteritis screened for aortic structural damage (aneurysm or dilatation). Ann Rheum Dis. 2014;73(10):1826-32.

3. Garcia-Martinez A, Hernandez-Rodriguez J, Arguis P, Paredes P, Segarra M, Lozano E, et al. Development of aortic aneurysm/dilatation during the followup of patients with giant cell arteritis: a cross-sectional screening of fifty-four prospectively followed patients. Arthritis Rheum. 2008;59(3):422-30.

4. Nuenninghoff DM, Hunder GG, Christianson TJ, McClelland RL, Matteson EL. Mortality of large-artery complication (aortic aneurysm, aortic dissection, and/or large-artery stenosis) in patients with giant cell arteritis: a population-based study over 50 years. Arthritis Rheum. 2003;48(12):3532-7.

5. Kermani TA, Warrington KJ, Crowson CS, Ytterberg SR, Hunder GG, Gabriel SE, et al. Large-vessel involvement in giant cell arteritis: a population-based cohort study of the incidence-trends and prognosis. Ann Rheum Dis. 2013;72(12):1989-94.

6. Evans JM, Bowles CA, Bjornsson J, Mullany CJ, Hunder GG. Thoracic aortic aneurysm and rupture in giant cell arteritis. A descriptive study of 41 cases. Arthritis Rheum. 1994;37(10):1539-47.

7. Nuenninghoff DM, Hunder GG, Christianson TJ, McClelland RL, Matteson EL. Incidence and predictors of large-artery complication (aortic aneurysm, aortic dissection, and/or large-artery stenosis) in patients with giant cell arteritis: a population-based study over 50 years. Arthritis Rheum. 2003;48(12):3522-31.

8. Kermani TA, Warrington KJ, Crowson CS, Hunder GG, Ytterberg SR, Gabriel SE, et al. Predictors of Dissection in Aortic Aneurysms From Giant Cell Arteritis. J Clin Rheumatol. 2016;22(4):184-7. 
9. de Boysson H, Daumas A, Vautier M, Parienti JJ, Liozon E, Lambert M, et al. Large-vessel involvement and aortic dilation in giant-cell arteritis. A multicenter study of 549 patients. Autoimmun Rev. 2018;17(4):391-8.

10. Gribbons KB, Ponte C, Carette S, Craven A, Cuthbertson D, Hoffman GS, et al. Patterns of Arterial Disease in Takayasu Arteritis and Giant Cell Arteritis. Arthritis Care Res (Hoboken). 2020;72(11):1615-24.

11. Wilson JC, Sarsour K, Collinson N, Tuckwell K, Musselman D, Klearman M, et al. Serious adverse effects associated with glucocorticoid therapy in patients with giant cell arteritis (GCA): A nested case-control analysis. Semin Arthritis Rheum. 2017;46(6):819-27.

12. Proven A, Gabriel SE, Orces C, O'Fallon WM, Hunder GG. Glucocorticoid therapy in giant cell arteritis: duration and adverse outcomes. Arthritis Rheum. 2003;49(5):703-8.

13. Therkildsen P, Nielsen BD, de Thurah A, Hansen IT, Norgaard M, Hauge EM. All-cause and causespecific mortality in patients with giant cell arteritis: a nationwide, population-based cohort study. Rheumatology. 2021. doi:10.1093/rheumatology/keab507. Online ahead of print.

14. Mackie SL, Dejaco C, Appenzeller S, Camellino D, Duftner C, Gonzalez-Chiappe S, et al. British Society for Rheumatology guideline on diagnosis and treatment of giant cell arteritis. Rheumatology. 2020;59(3):e1-23.

15. Hellmich B, Agueda A, Monti S, Buttgereit F, de Boysson H, Brouwer E, et al. 2018 Update of the EULAR recommendations for the management of large vessel vasculitis. Ann Rheum Dis. 2020;79(1):19-30.

16. Maz M, Chung SA, Abril A, Langford CA, Gorelik M, Guyatt G, et al. 2021 American College of Rheumatology/Vasculitis Foundation Guideline for the Management of Giant Cell Arteritis and Takayasu Arteritis. Arthritis Care Res (Hoboken). 2021;73(8):1071-87.

17. Sugihara T, Hasegawa H, Uchida HA, Yoshifuji H, Watanabe Y, Amiya E, et al. Associated factors of poor treatment outcomes in patients with giant cell arteritis: clinical implication of large vessel lesions. Arthritis Res Ther. 2020;22(1):72.

18. Stone JH, Tuckwell K, Dimonaco S, Klearman M, Aringer M, Blockmans D, et al. Trial of Tocilizumab in Giant-Cell Arteritis. N Engl J Med. 2017;377(4):317-28.

19. de Boysson H, Liozon E, Lambert M, Parienti JJ, Artigues N, Geffray L, et al. 18F-fluorodeoxyglucose positron emission tomography and the risk of subsequent aortic complications in giant-cell arteritis: A multicenter cohort of 130 patients. Medicine. 2016;95(26):e3851.

20. de Boysson H, Espitia O, Samson M, Tieulie N, Bachmeyer C, Moulinet T, et al. Giant cell arteritisrelated aortic dissection: A multicenter retrospective study. Semin Arthritis Rheum. 2021;51(2):4305.

21. Aouba A, Gonzalez Chiappe S, Eb M, Delmas C, de Boysson H, Bienvenu B, et al. Mortality causes and trends associated with giant cell arteritis: analysis of the French national death certificate database (1980-2011). Rheumatology. 2018;57(6):1047-55. 
22. de Boysson H, Liozon E, Espitia O, Daumas A, Vautier M, Lambert M, et al. Different patterns and specific outcomes of large-vessel involvements in giant cell arteritis. J Autoimmun.

2019;103:102283.

23. Imfeld S, Aschwanden M, Rottenburger C, Schegk E, Berger CT, Staub D, et al. [18F]FDG positron emission tomography and ultrasound in the diagnosis of giant cell arteritis: congruent or complementary imaging methods? Rheumatology. 2020;59(4):772-8.

24. Quinn KA, Ahlman MA, Malayeri AA, Marko J, Civelek AC, Rosenblum JS, et al. Comparison of magnetic resonance angiography and (18)F-fluorodeoxyglucose positron emission tomography in large-vessel vasculitis. Ann Rheum Dis. 2018;77(8):1165-71.

25. Muratore F, Kermani TA, Crowson CS, Green AB, Salvarani C, Matteson EL, et al. Large-vessel giant cell arteritis: a cohort study. Rheumatology. 2015;54(3):463-70.

26. Michailidou D, Rosenblum JS, Rimland CA, Marko J, Ahlman MA, Grayson PC. Clinical symptoms and associated vascular imaging findings in Takayasu's arteritis compared to giant cell arteritis. Ann Rheum Dis. 2020;79(2):262-7.

27. Kermani TA, Sreih AG, Cuthbertson D, Carette S, Hoffman GS, Khalidi NA, et al. Evaluation of damage in giant cell arteritis. Rheumatology. 2018;57(2):322-8.

28. Mainbourg S, Addario A, Samson M, Puechal X, Francois M, Durupt S, et al. Prevalence of Giant Cell Arteritis Relapse in Patients Treated With Glucocorticoids: A Meta-Analysis. Arthritis Care Res (Hoboken). 2020;72(6):838-49.

29. Kermani TA, Diab S, Sreih AG, Cuthbertson D, Borchin R, Carette $S$, et al. Arterial lesions in giant cell arteritis: A longitudinal study. Semin Arthritis Rheum. 2019;48(4):707-13.

30. Reichenbach S, Adler S, Bonel H, Cullmann JL, Kuchen S, Butikofer L, et al. Magnetic resonance angiography in giant cell arteritis: results of a randomized controlled trial of tocilizumab in giant cell arteritis. Rheumatology. 2018;57(6):982-6.

31. Grayson PC, Alehashemi S, Bagheri AA, Civelek AC, Cupps TR, Kaplan MJ, et al. (18) FFluorodeoxyglucose-Positron Emission Tomography As an Imaging Biomarker in a Prospective, Longitudinal Cohort of Patients With Large Vessel Vasculitis. Arthritis Rheumatol. 2018;70(3):439-49.

32. Schonau V, Roth J, Tascilar K, Corte G, Manger B, Rech J, et al. Resolution of vascular inflammation in patients with new-onset giant cell arteritis: data from the RIGA study. Rheumatology. 2021;60(8):3851-61.

33. Seitz L, Christ L, Lotscher F, Scholz G, Sarbu AC, Butikofer L, et al. Quantitative ultrasound to monitor the vascular response to tocilizumab in giant cell arteritis. Rheumatology. 2021. doi:10.1093/rheumatology/keab484. Online ahead of print.

34. Quinn KA, Dashora H, Novakovich E, Ahlman MA, Grayson PC. Use of 18F-fluorodeoxyglucose positron emission tomography to monitor tocilizumab effect on vascular inflammation in giant cell arteritis. Rheumatology. 2021;60(9):4384-9.

35. Kermani TA, Warrington KJ, Cuthbertson D, Carette S, Hoffman GS, Khalidi NA, et al. Disease Relapses among Patients with Giant Cell Arteritis: A Prospective, Longitudinal Cohort Study. J 
Rheumatol. 2015;42(7):1213-7.

36. Stone JH, Tuckwell K, Dimonaco S, Klearman M, Aringer M, Blockmans D, et al. Glucocorticoid Dosages and Acute-Phase Reactant Levels at Giant Cell Arteritis Flare in a Randomized Trial of Tocilizumab. Arthritis Rheumatol. 2019;71(8):1329-38.

37. Gribbons KB, Ponte C, Craven A, Robson JC, Suppiah R, Luqmani R, et al. Diagnostic Assessment Strategies and Disease Subsets in Giant Cell Arteritis: Data From an International Observational Cohort. Arthritis Rheumatol. 2020;72(4):667-76.

38. Spiera R, Unizony SH, Bao M, Luder Y, Han J, Pavlov A, et al. Tocilizumab vs placebo for the treatment of giant cell arteritis with polymyalgia rheumatica symptoms, cranial symptoms or both in a randomized trial. Semin Arthritis Rheum. 2021;51(2):469-76.

\section{Figures}


A

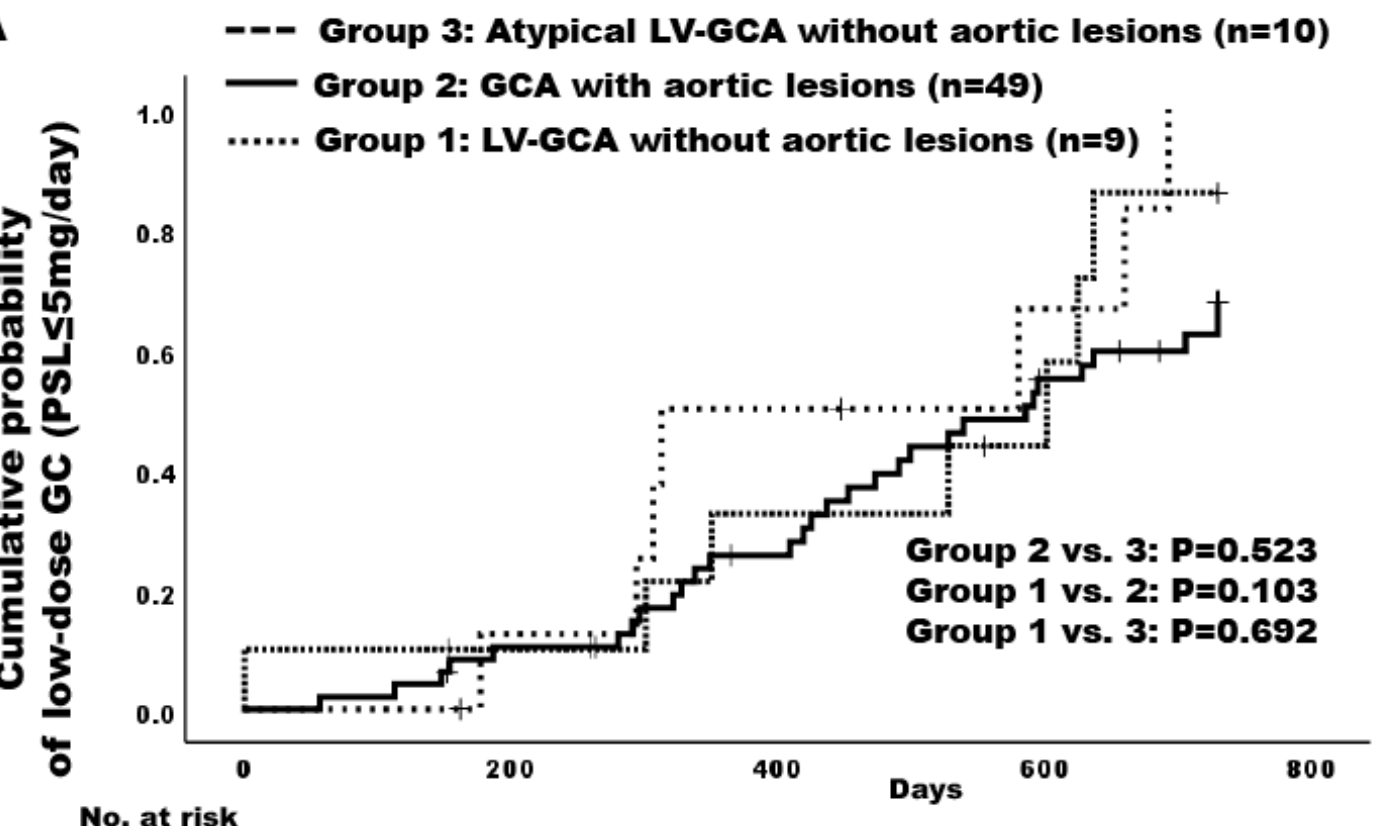

No. at risk

$\begin{array}{lllllllll}\text { Group 3 } & 10 & 9 & 8 & 8 & 6 & 6 & 4 & 1 \\ \text { Group 2 } & 49 & 48 & 43 & 38 & 33 & 25 & 19 & 15 \\ \text { Group 1 } & 9 & 9 & 8 & 6 & 4 & 3 & 2 & 0\end{array}$

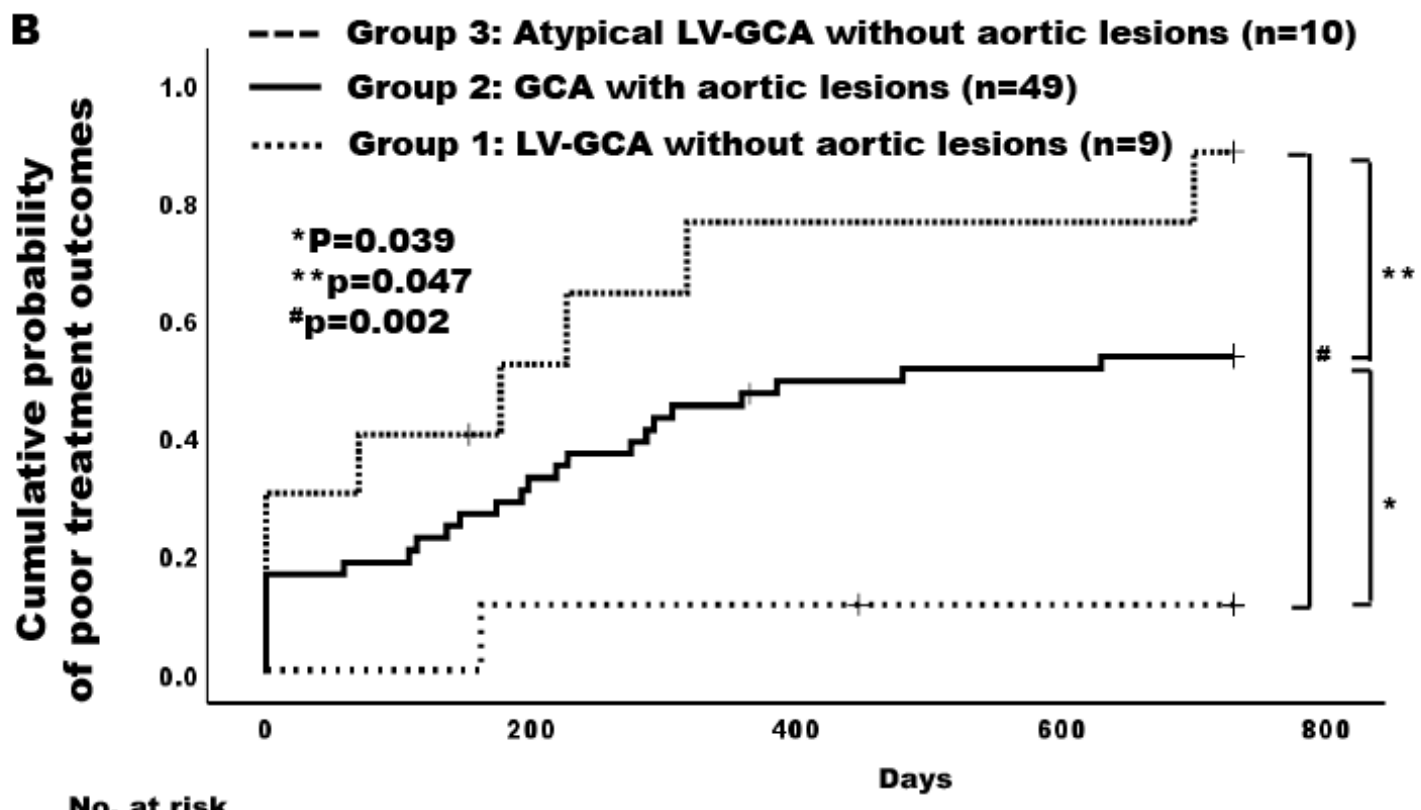

No. at risk

$\begin{array}{lllllllll}\text { Group 3 } & 10 & 6 & 4 & 3 & 2 & 2 & 2 & 0 \\ \text { Group 2 } & 49 & 39 & 33 & 28 & 24 & 23 & 23 & 21 \\ \text { Group 1 } & 9 & 9 & 8 & 8 & 8 & 7 & 7 & 6\end{array}$

Figure 1

Differential treatment response among 3 groups Cumulative rate of achievement of low-dose GCs (PSL $\leq 5 \mathrm{mg} /$ day) (A) and event of poor treatment response (B) were assessed by the Kaplan-Meier method and the log-rank test. Group 1: subclavian artery lesions without aortic lesions (LV-GCA without aortic lesions); Group 2: aortic lesions with or without subclavian artery lesions (GCA with aortic lesions); Group 
Week 0

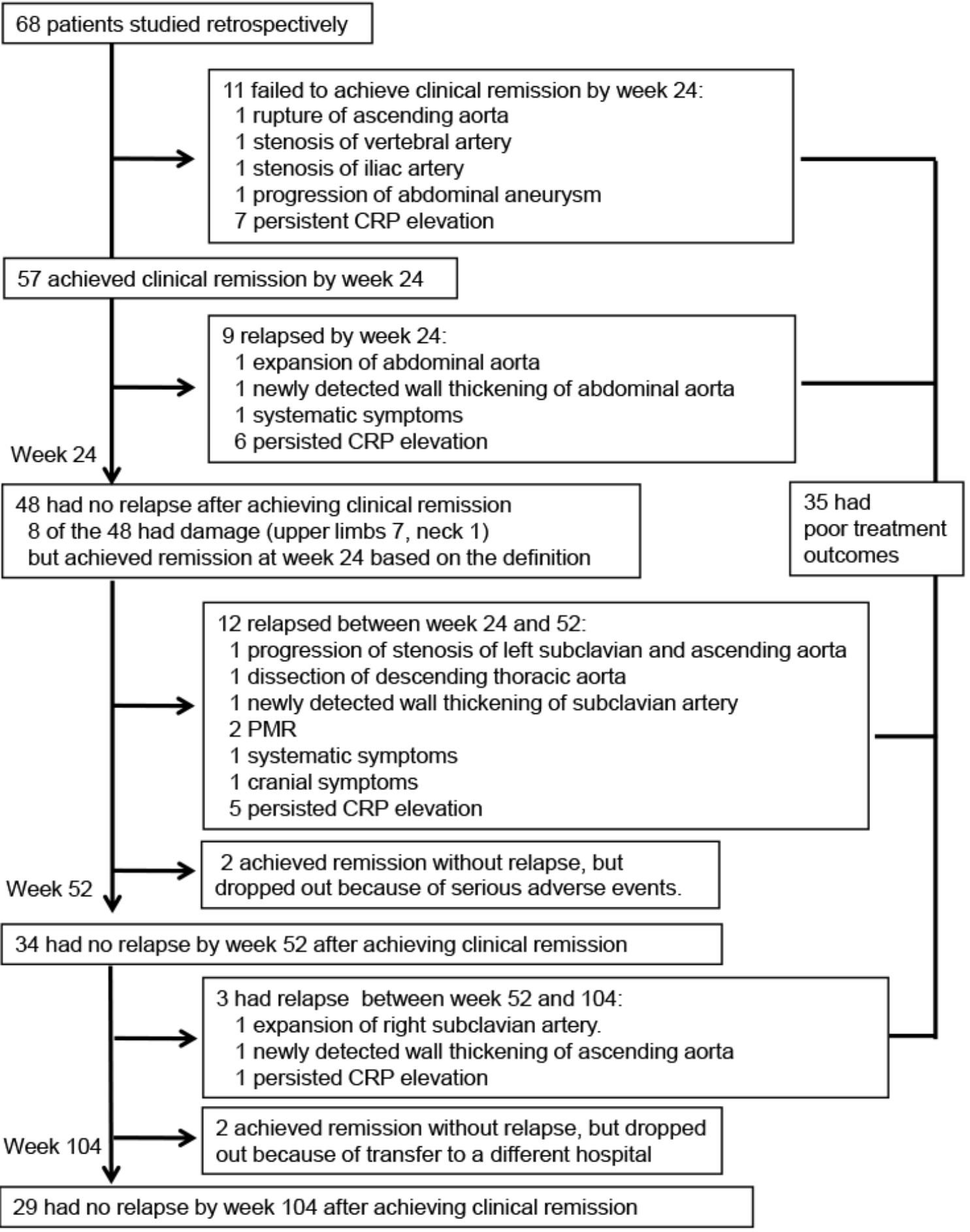

Figure 2

Screening, follow-up of the patients, and treatment outcomes. Clinical remission and relapse were evaluated in 68 newly-diagnosed patients with LVLs. Eleven had worsening of clinical signs and symptoms or persisted elevation of CRP and were not able to achieve clinical remission. Nine had relapse 
after achievement of clinical remission between week 0 and 24, and 48 had no relapse at week 24 after achievement of clinical remission. Twelve had relapse between week 24 and 52, and three between 52 and 104. Finally, 29 had no relapse throughout 104 weeks after achievement of clinical remission at week 24. Overall, 35 had poor treatment outcome. GCs: glucocorticoids; LV: large-vessel; LVLs: large-vessel lesions. 